\title{
Reflexões bioéticas sobre a eutanásia a partir de caso paradigmático
}

Daniel Abreu Santos ${ }^{1}$, Eduardo Robatto Plessim de Almeida ${ }^{2}$, Felipe Freire da Silva ${ }^{3}$, Layo Henrique Carvalho Andrade ${ }^{4}$, Leandro Anton de Azevêdo ${ }^{5}$, Nedy Maria Branco Cerqueira Neves ${ }^{6}$

\section{Resumo}

Recentemente, na cidade de Curitiba/PR, ocorreu um fato que gerou grande repercussão nacional e suscitou questões acerca da "eutanásia", tema controverso e pouco debatido na população em geral, o que motivou a realização deste artigo. $O$ objetivo do trabalho consiste em analisar aspectos envolvidos no processo de morrer: eutanásia e ortotanásia e sua relação com o princípio bioético da autonomia. Trata-se de revisão reflexiva de literatura tendo como base matéria publicada na imprensa, abordando a visão de um grupo de acadêmicos de medicina a respeito do tema. A eutanásia é considerada uma prática ilegal segundo o Código Penal brasileiro e vai de encontro aos princípios éticos da medicina. A ortotanásia não deve se confundir com aquela prática, encaixando-se como opção legítima a ser adotada por pacientes com doença terminal em intenso sofrimento físico e psíquico.

Palavras-chave: Eutanásia. Ortotanásia. Distanásia. Bioética. Autonomia profissional. Autonomia pessoal.

\section{Resumen}

\section{Reflexiones bioéticas acerca de la eutanásia a partir de un caso paradigmático}

Recientemente, en la ciudad de Curitiba/PR, se produjo un evento que generó gran impacto nacional y planteó dudas sobre la "eutanasia", un tema controvertido y rara vez discutido en la población general, lo que ha llevado a la realización de este trabajo. El objetivo de este trabajo consiste en analizar los aspectos bioéticos implicados en el proceso de la muerte: eutanasia, ortotanasia y el principio de la autonomía. Se trata de una revisión reflexiva de la literatura basada en un artículo publicado en la prensa, abordando la visión de un grupo de estudiantes de medicina acerca del tema. Se considera la eutanasia una práctica ilegal según lo que se prevé en la legislación brasileña y está en contra los principios éticos de la medicina. La ortotanasia no debe ser confundida con aquella práctica, adecuándose como una opción legítima a ser adoptada por los pacientes con una enfermedad terminal en intenso sufrimiento físico y psíquico.

Palabras-clave: Eutanasia. Ortotanasia. Futilidad. Bioética. Autonomía profisional. Autonomía personal.

\section{Abstract \\ Bioethical reflections on euthanasia: analysis of a paradigmatic case}

Recently, a fact that occurred in the city of Curitiba/PR caused a huge national impact and raised questions about euthanasia, a controversial topic that is rarely discussed by the population, what led the realization of this article. The objective of this work is to analyze bioethical aspects involved in death process: euthanasia, orthotanasia and the principle of autonomy. This is a reflective literature review based on an article published in the media that shows the point of view of medical students on this topic. The euthanasia is considered an illegal practice according to national legislation and goes against the medicine principles, since the professionals in this field are trained to work for the maintenance of life. Orthotanasia should not be confused with that practice, and it seems to be the best way to be adopted by patients with terminal diseases and intense mental and physical pain.

Key words: Euthanasia. Orthothanasia. Dysthanasia. Bioethics. Professional autonomy. Personal autonomy.

1. Graduando dansantos18@hotmail.com 2. Graduando eduardoplessim@gmail.com 3. Graduando felipefreire_silva@hotmail.com 4. Graduando layo_andrade@hotmail.com 5. Graduando leandro_azevedo89@hotmail.com 6. Doutora nedyneves@terra.com.br-Escola Bahiana de Medicina e Saúde Pública, Salvador/BA, Brasil. 
"Quem não sabe o que é a vida, como poderá saber o que é a morte?"

Confúcio $^{1}$

O homem vive um ciclo imutável de morte. Entretanto, discuti-la é algo evitado e fomentador de polêmicas. É inegável que a significância do conceito morte sofre influência de concepções religiosas, filosóficas e culturais, o que gera, desta forma, visões multifacetadas e, por conseguinte, conflitantes ${ }^{2,3}$. Notavelmente, a população leiga, em geral, possui dificuldades em discernir o significado de morte encefálica e paciente com doença em estado terminal. Segundo a literatura, tal situação extrapola para a classe médica especializada, para a qual ainda há desconhecimento em relação aos critérios preconizados para definir morte encefálica ${ }^{4}$, estabelecida pela comunidade científica como uma perda irreversível das funções do cérebro e tronco encefálico ${ }^{5}$.

Segundo Robatto ${ }^{6}$, pode-se considerar uma doença como terminal quando, na sua evolução, apesar de todos os recursos médicos disponíveis, o paciente não apresenta condições de prolongar a sobrevida, estando, portanto, em um processo de morte inevitável. A eutanásia é um dos assuntos mais delicados da ética médica contemporânea ${ }^{7}$. 0 termo, concebido em 1623 pelo filósofo Francis Bacon, significa, conforme sua etimologia, "boa morte" ${ }^{8}$, e caracteriza-se pela abreviação da vida por solicitação do paciente ${ }^{9}$.

\section{Eutanásia realmente é "boa morte"?}

O fato é que no Brasil, de acordo com o artigo 121 do Código Penal, a eutanásia é considerada homicídio, conceito que se aplica em diversos outros países ${ }^{10}$. Recentemente, em Curitiba, ocorreu um fato que gerou grande repercussão nacional: o caso de uma médica intensivista acusada de desligar aparelhos de pacientes terminais na UTI em que trabalhava. Esse acontecimento suscitou questões acerca da "eutanásia", o que motivou a realização desta revisão de literatura, visto se tratar de tema controverso e pouco debatido na população em geral.

Assim, o objetivo deste trabalho consiste em realizar uma análise dos aspectos bioéticos envolvidos no processo de morrer, especificamente a eutanásia, a ortotanásia e o princípio da autonomia, tendo como pano de fundo uma reflexão crítica sobre o ocorrido em 2013 com a médica paranaense.

\section{Método}

Trata-se de pesquisa de revisão reflexiva de literatura, tendo como pilar fomentador de estudo a prática da médica paranaense que ganhou a mídia brasileira no dia 11 de março de 2013 com a matéria intitulada: "Médica acusada de desligar aparelhos de pacientes terminais concede primeira entrevista" 11.

Como fontes de pesquisa foram utilizados livros, revistas e artigos científicos que preenchiam os seguintes critérios: abordavam a temática da eutanásia e os aspectos bioéticos envolvidos, possuíam como metodologia a revisão narrativa de literatura e foram escritos na língua portuguesa (Brasil). Como fontes de busca, os bancos de dados virtuais SciELO e Lilacs. As seguintes palavras foram abordadas como descritores: eutanásia, ortotanásia, distanásia, princípios da bioética e autonomia. No SciELO foram encontrados sete artigos ao se utilizar os descritores eutanásia AND ortotanásia AND distanásia. Outros nove artigos foram encontrados ao se utilizar como descritores os termos eutanásia AND bioética AND autonomia. Idêntico procedimento foi feito no Lilacs, encontrando-se 10 artigos com o primeiro grupo de descritores e 20 com o segundo. Desse modo, foram inicialmente selecionados 46 artigos. Foram excluídos artigos em outros idiomas e aqueles que, apesar de apresentarem os descritores, não abordavam a temática proposta. Ao final da busca foram selecionados 14 artigos. Essa revisão bibliográfica possibilitou o embasamento teórico sobre o assunto, permitindo fomentar o desenvolvimento do trabalho.

É relevante ressaltar que este estudo teve como base o conteúdo divulgado publicamente pela mídia, vez que não houve acesso aos autos éticos e legais que tratam do caso, haja vista que o processo corre em sigilo judicial e não foram fornecidas maiores informações acerca do inquérito. Em decorrência, trata-se de estudo de fonte secundária, que perpassa a interpretação da mídia, a qual, em alguma medida, reflete os estereótipos que moldam o senso comum acerca da temática.

\section{Discussão}

A morte é um evento final e inevitável de todo ser vivo. É um processo flagrado rotineiramente pelas pessoas que lidam com a vida, sobretudo os profissionais da área da saúde, formados e "preparados" para evitá-la a todo custo. Apesar de a formação acadêmica preconizar o desenvolvimento 
de habilidades que possibilitem ao estudante lidar com a dor e a morte como um ofício, certamente encontram-se notórias dificuldades nesse âmbito ${ }^{12}$. Isso ocorre em grande parte como decorrência do interdito social em relação à morte, cada vez mais negada em sua essência, à medida que a ciência consolida seu poder no imaginário. A ciência, por sua vez, reproduz um paradoxo: mesmo diante de constante evolução, ainda não consegue propiciar respostas suficientes sobre os fatos que circundam a morte. Em decorrência, o tema permanece cercado por discussões calorosas e controversas em vários ramos da sociedade, como religião, bioética, política e a própria ciência.

A bioética é o campo interdisplinar que enfo$\mathrm{ca}$ as questões referentes à vida humana, definindo princípios em prol da vida e da saúde. Um deles refere-se ao princípio da autonomia, cujos pressupostos facultam à pessoa a liberdade para decidir sobre o que considera bom ou não para si ${ }^{13,14}$. As escolhas individuais do paciente, portanto, devem ser tratadas com respeito pela sua capacidade de decisão frente aos atos médicos, diagnósticos ou terapêuticos, que devem ser autorizados pelo mesmo ${ }^{15}$.

O moderno debate bioético sobre a eutanásia repousa, em grande medida, na polarização entre os princípios do respeito à autonomia individual e da sacralidade da vida. $O$ direito de morrer se basearia no princípio da autonomia ${ }^{13,16}$ : Ó doçura da vidaAgoniza a toda a hora sob a pena da morte, em vez de morrer de um só golpe ${ }^{17}$.

\section{Há o direito de morrer?}

No Brasil, a eutanásia é considerada prática ilegal, segundo o previsto pela legislação nacional, no art. $121 \S 1^{\circ}$ do Código Penal ${ }^{10}$. Em países como a Holanda e Bélgica, sua realização é permitida ${ }^{18,19} \mathrm{e}$, nestes contextos, a caracterização do ato, segundo Goldim ${ }^{20}$, pode ser subdividida em ativa e passiva (ou indireta). A eutanásia ativa ocorre quando o médico produz diretamente a morte do paciente com doença em fase terminal, enquanto a passiva se dá mediante omissão, ou seja, pela ausência de ação do médico ${ }^{6,20}$.

Quanto ao consentimento do paciente, Morais ${ }^{9}$ classifica a eutanásia como voluntária, não voluntária e involuntária. A voluntária ocorre quando o enfermo expressa o seu desejo de morrer, enquanto a não voluntária refere-se a situações nas quais não se sabe a opinião do paciente. A involuntária, por sua vez, acontece contra a vontade deste, se associando mais intensamente com o homicídio doloso ${ }^{9,20}$. É de suma importância ressaltar, contudo, que na literatura existem diversas classificações da eutanásia, havendo considerável divergência ${ }^{20}$.

No meio médico, a abordagem mais adequada em pacientes terminais é a ortotanásia. Tal prática aceita o curso natural de morte mediante a adoção de cuidados paliativos, evitando procedimentos desnecessários que apenas iriam prolongar o sofrimento do paciente, constituindo o limite de esforço terapêutico ${ }^{21}$.

Eutanásia como solução para "desentulhar" leitos do sistema público de saúde?

No tocante à prática da eutanásia, em fevereiro de 2013 uma médica paranaense foi acusada de homicídio doloso por desligar aparelhos que mantinham a vida dos pacientes na unidade de terapia intensiva (UTI) do Hospital Evangélico de Curitiba ${ }^{11}$. Este caso trouxe à tona antiga discussão pautada nos princípios bioéticos relacionados com a autonomia do médico e do paciente, no que se refere à decisão do momento certo de morrer. Segundo o inquérito policial, que se baseia em denúncias de ex-funcionários e escutas telefônicas, a médica afirmou, entre outras coisas, que queria "desentulhar" a UTI e referiu "desligar" pacientes ${ }^{11}$.

O Brasil, configurando-se como um país em desenvolvimento e cujo sistema de saúde opera, na maioria das vezes, em condições precárias, enfrenta grave problema de insuficiência de leitos nos grandes hospitais públicos, decorrente tanto da falta de recursos humanos quanto de aporte financeiro ${ }^{3}$. Nesse contexto adverso, a legalização da eutanásia poderia ser pleiteada como forma de aumentar a disponibilidade de vagas em UTI, previamente ocupadas por pacientes terminais, além de interferir na política da doação de órgãos, contribuindo para a ampliação deste campo ${ }^{22}$.

A situação precária de nossa saúde pública, traduzida pela carência de recursos/leitos, não deve servir de justificativa para a adoção de práticas criminosas, como a abreviação da vida de um ser humano em situação de fragilidade, atitude que descaracteriza totalmente a prática médica, estabelecendo, inclusive, o total descrédito da medicina.

Se tal proposta pode ser considerada heterodoxa não deixa de ser também preocupante, especialmente em uma sociedade na qual a ética assume cada vez mais um caráter relativo; onde a linha que divide o princípio da beneficência médica e a banalização da morte é tênue. Assim, pode-se questionar a seriedade da política que regeria tais ações, 
as quais necessitariam rigoroso controle. Acima de tudo, é inconcebível a ideia de desprezar vidas como meros objetos mercantis.

O princípio bioético da autonomia garante o direito de autodeterminação e a capacidade de gerenciamento de toda e qualquer pessoa ${ }^{13,14,16}$. Entretanto, até que ponto o paciente com doença terminal, inserido no universo da enfermidade incurável ${ }^{23}$, tem integridade mental para discernir sobre a própria existência? Dessa forma, a eutanásia vai de encontro ao princípio basilar que rege a prática médica - o juramento de Hipocrátes ${ }^{24}$ : Aplicarei os regimes para o bem do doente segundo o meu poder e entendimento, nunca para causar dano ou mal a alguém. A ninguém darei por comprazer, nem remédio mortal nem um conselho que induza a perda ${ }^{25}$.

No outro extremo, considerando-se a vida em sua sacralidade, tenta-se mantê-la a qualquer custo com procedimentos exaustivos e ineficazes. Ante a irreversibilidade da condição clínica do paciente, pratica-se, então, a distanásia ${ }^{26}$.

\section{O prolongamento da vida pode 'fazer mal' ao pa- ciente?}

Em 2012, o Conselho Federal de Medicina aprovou a Resolução CFM $1.995^{27}$, que dispõe sobre as diretivas antecipadas de vontade dos pacientes, deixando claro que o paciente tem autonomia, junto ao seu médico, de decidir sobre a não realização de procedimentos inúteis em fase de terminalidade da vida. A resolução assegura ao paciente o direito de não prolongar seu sofrimento. Essa prerrogativa apoia a ideia de que a distanásia é algo inaceitável e cruel, sendo estarrecedora a constatação de que é prática médica frequente nas unidades de terapia intensiva ${ }^{28}$.

O princípio da beneficência norteia a essência das condutas médicas, visando garantir a saúde do paciente e o seu bem-estar ${ }^{13}$. A distanásia propõe o ato de prolongar a vida dos enfermos considerados incuráveis, situados em um contexto de sobejo sofrimento, tanto físico como emocional e psíquico. Prolongar a vida de um paciente nessa condição certamente não significa promover a beneficência. Pelo contrário, pode-se estar a ampliar exageradamente os seus momentos de dor e desconforto, o que vai de encontro ao que se objetiva na prática médica, ou seja, assegurar o bem-estar do paciente ${ }^{29}$.

É nesse contexto que se pensa na ortotanásia como a via intermediária e mais adequada para o cuidado dos pacientes com doença terminal. A or- totanásia é aceita como a conduta médica lícita do ponto de vista jurídico, desde que não signifique redução do período natural de vida do paciente nem caracterize abandono de incapaz ${ }^{22}$.

Assim, é indispensável constatar que a ação da médica paranaense reflete a falta de princípios éticos e humanos enraizada na sociedade. Vale considerar a doença terminal como o estado mais degradante da essência humana, de forma que cada paciente deve ser tratado de maneira singular, segundo suas necessidades físicas, psicológicas e espirituais. Permitir ações como a praticada pela referida médica é o mesmo que atentar contra os valores e princípios morais que mantêm a sociedade brasileira, abrindo espaço para outras distorções morais similares ou de maior impacto contra a vida.

\section{Ser médico: a dor e a morte como ofício}

A literatura apresenta conteúdo abrangente sobre pacientes em fase terminal. Todavia, pouco se aborda a dinâmica que envolve o manejo dos mesmos ${ }^{30}$. Até que ponto a vontade do paciente, da família e do médico, dentro de suas pluralidades e interesses religiosos, culturais, socioeconômicos e bioéticos, podem interferir na conduta terapêutica? Nessa ótica, é possível que a eutanásia, na medicina, seja prática bem mais frequente do que o presumível, ainda que ilegal. Este argumento, por si só, enseja a ampliação de discussão e aprofundamento do tema nos meios médico e acadêmico.

$\mathrm{O}$ processo de morte traz consigo conflitos e angústias humanas com os quais o estudante-profissional de saúde irá, inevitavelmente, lidar durante toda a carreira. Deve ser, portanto, devidamente preparado para suprir sua própria fragilidade, de forma a estabelecer uma relação interpessoal humanizada, segura, honesta e cautelosa, conferindo, assim, conforto ao paciente e seus familiares diante dessa delicada situação.

A morte é a indelével certeza da condição humana, embora quase sempre recalcada, constituindo intrínseca peculiaridade do Homo sapiens sapiens, o único vivente que tem a consciência da própria finitude ${ }^{31}$.

\section{Considerações finais}

Ante a complexidade do tema, este trabalho não pretende esgotar a discussão. Ao contrário, visa estimular o aprofundamento da temática, considerando sua importância social. Caso se confirmem as 
notícias divulgadas na imprensa, um aspecto relevante refere-se ao descumprimento do Código de Ética Médica (CEM) pela profissional, dado que o artigo 41 veda ao médico abreviar a vida do paciente, ainda que a seu pedido ou de seu representante legal. O inciso XXII, do mesmo documento, também terá sido violado, visto que destaca o dever profissional em propiciar aos pacientes todos os cuidados paliativos apropriados na vigência de situações clínicas irreversíveis e terminais ${ }^{32}$. Assim, a situação analisada se revelaria inaceitável considerando-se, estritamente, o cumprimento das normas deontológicas da profissão.

A eutanásia, além de ilícita no Brasil, nega dois princípios éticos de suma importância para a medicina - a beneficência e a não maleficência -, visto que os profissionais dessa área, em geral, são capacitados para atuar visando o bem-estar e a manutenção da vida dos pacientes. E é em nome da manutenção da vida que eles, muitas vezes, extrapolam suas atribuições, utilizando desmesuradamente artifícios para a manutenção da vida: a obstinação terapêutica. Entretanto, estudos têm apontado que a formação adequada, voltada ao bem-estar do paciente, promove melhores resultados, conferindo um processo de morte mais harmonioso. A ortotanásia encaixa-se nessa linha de práticas como a meIhor escolha para pacientes com doenças em estado terminal, com intenso sofrimento físico e psíquico.

No que tange ao caso analisado neste artigo, é importante informar que a profissional que pro- tagonizou esses eventos está respondendo tanto a processo judicial como a processo ético-profissional no Conselho Regional de Medicina do Estado do Paraná. Segundo o entendimento do Ministério Público, a profissional, que esteve presa por um mês, deveria ser novamente detida para garantir a ordem pública e a conveniência da instrução do processo ${ }^{33}$. Em março de 2014, porém, a 1ª̂mara do Tribunal de Justiça do Paraná (TJ-PR) negou em julgamento o recurso do Ministério Público e o pedido de retorno à prisão.

Por fim, é importante ressaltar que a atividade médica deve ser respaldada no legado hipocrático que ensina a curar quando possível, aliviar quando necessário, consolar sempre ${ }^{34}$. Então, deve partir dos profissionais de saúde - e estender-se à sociedade como um todo - a compreensão de que a morte é condição intrínseca à natureza dos seres vivos, a qual todos estão fadados. Sua inevitabilidade implica considerar que o fenômeno perpassa e transcende traços culturais, princípios éticos e pressupostos científicos relacionados a contextos e períodos históricos definidos. Na atualidade, configura-se tema polêmico em vista do fato de as sociedades negarem peremptoriamente o fenômeno, o que se reflete na formação das áreas acadêmicas da saúde e na prática dos serviços que lidam diretamente com ela. Assim, urge refletir sobre essa temática para transformar a percepção e as práticas relativas à morte e ao morrer ${ }^{35}$, sem confundir processos legítimos, como a ortotanásia, e ilegítimos, como a eutanásia, como se pretendeu nesta discussão.

\section{Referências}

1. Livrateria E-books. 450 frases fantásticas. [Internet]. Rio de Janeiro: Livrateria; 2013 (acesso 20 maio 2013). Disponível: http://www.livrateria.com.br/media/mconnect_uploadfiles/4/5/450fras esfantasticas_sample.pdf

2. Siqueira-Batista R, Schramm FR. Eutanásia: pelas veredas da morte e da autonomia. Ciênc Saúde Coletiva. 2004;9(1):31-41.

3. Oliveira HB, Oliveira EFB, Oliveira RZB, Oliveira AMB, Santos MERC, Silva JAP. Ética e eutanásia. J Vasc Br. 2003;2(3):278-82.

4. Meneses EA, Souza MFB, Baruzzi RM, Prado MM, Garrafa V. Análise bioética do diagnóstico de morte encefálica e da doação de órgãos em hospital público de referência do Distrito Federal. Rev. bioét. (Impr.). 2010;18(2):397-412.

5. Wijdicks EF. The diagnosis of brain death. N Engl J Med. 2001;344:1.215-21.

6. Robatto W. Eutanásia: sim ou não? Aspectos bioéticos. $2^{\mathrm{a}}$ ed. Salvador: Empresa Gráfica da Bahia; 2008.

7. Arus MA, Leite CSM, Teruchkin B. A atitude médica diante da morte em um hospital universitário. Rev AMRIGS. 1996;40(4):243-6.

8. Bacon F. História vitae et mortis. Rio de Janeiro: Vozes; 1963.

9. Morais IM. Autonomia pessoal e morte. Rev. bioét. (Impr.). 2010;18(2):289-309.

10. Revista dos Tribunais. Código Penal. $9^{a}$ ed. São Paulo: Revista dos Tribunais; 2004. p. 848.

11. Band News. Médica suspeita de mortes em UTI de Curitiba nega acusações. [Entrevista]. Band News; 2013 (acesso 30 abr. 2013). Disponível: http://bandnewsfm.band.uol.com.br/Noticia. aspx?COD $=652680 \&$ Tipo $=227$ 
12. Azeredo NSG, Rocha CF, Carvalho PRA. O enfrentamento da morte e do morrer na formação de acadêmicos de medicina. Rev Bras Educ Méd. 2011;35(1):37-43.

13. Beauchamp TL, Childress JF. Princípios de ética biomédica. $4^{\mathrm{a}}$ ed. São Paulo: Loyola; 2002.

14. Organização das Nações Unidas para a Educação, a Ciência e a Cultura. Declaração Universal sobre Bioética e Direitos Humanos. Paris: Unesco; 2005.

15. Guedes HTV. Antes de realizar um procedimento, obtenha, por escrito, a concordância do paciente. Vida e Ética. 2010;1:19.

16. Ribeiro DC. Autonomia: viver a própria vida e morrer a própria morte. Cad Saúde Pública. 2006;22(8):1.749-54.

17. Frases famosas. Frases de William Shakespeare. [Internet]. (acesso 19 maio 2013). Disponível: http://www.frasesfamosas.com.br/de/william-shakespeare/pag/9.html

18. Singer P. Voluntary euthanasia: a utilitarian perspective. Bioethics. 2003;17(5-6):526-41.

19. Pessini L. Lidando com pedidos de eutanásia: a inserção do filtro paliativo. Rev. bioét. (Impr.). 2010;18(3):549-60.

20. Goldim JR. Eutanásia. [Internet]. Núcleo Interinstitucional de Bioética; 2013 (acesso 18 maio 2013). Disponível: http://www.bioetica.ufrgs.br/eutanasi.htm

21. Moritz RD. Ortotanásia: o direito à morte no tempo certo. Ciência Hoje. 2013;301:64-5.

22. Marton S. Eutanásia: a favor ou contra? Revista Filosofia. 2007;IV(38):16-23.

23. Persistent Vegetative State. Medical aspects of the persistent vegetative state (1): the multisociety task force on PVS. New Engl J Med. 1994;330(21):1.499-508.

24. Abraão BS. História da filosofia. São Paulo: Nova Cultural; 1999.

25. Conselho Regional de Medicina do Estado de São Paulo. Juramento de Hipócrates. [Internet]. (acesso 25 jun. 2013) Disponível: http://www.cremesp.org.br/?siteAcao=Historia\&esc=3

26. Pessini L. Questões éticas-chave no debate hodierno sobre a distanásia. In: Pessini L, Garrafa V, organizadores. Bioética: poder e injustiça. São Paulo: Loyola; 2003. p. 389-408.

27. Conselho Federal de Medicina. Resolução CFM n 1.995, de 31 de agosto de 2012. Dispõe sobre as diretivas antecipadas de vontade dos pacientes. Brasília: CFM; 2012.

28. Pessini L. Distanásia: por que prolongar o sofrimento? Ciência Hoje. 2013;301:61-3.

29. Castilho EA, Kalil J. Ética e pesquisa médica: princípios, diretrizes e regulamentações. Rev Soc Bras Med Trop. 2005;38(4)344-7.

30. Kipper DJ. Medicina e os cuidados de final de vida: uma perspectiva brasileira e latino-americana. In: Pessini L, Garrafa V, organizadores. Bioética: poder e injustiça. São Paulo: Loyola; 2004. p. 40914.

31. Freud S. Sigmund Freud: obra completa. Rio de Janeiro: Imago; 2009. v. 14.

32. Conselho Federal de Medicina. Resolução CFM n 1.931, de 24 de setembro de 2009. Código de ética médica. [Internet]. Brasília: CFM; 2009 (acesso 22 maio 2014). Disponível: http://www. portalmedico.org.br/resolucoes/cfm/2009/1931_2009.htm

33. Trisotto F. TJ-PR avalia recurso do caso Virgínia na quinta (20). [Internet]. Londrina: Gazeta do Povo; 2014 (acesso 21 maio 2014). Disponível: http://www.gazetadopovo.com.br/vidaecidadania/ conteudo. phtml?id=1455286

34. Rezende JM. Curar algumas vezes, aliviar muitas vezes, consolar sempre. [Internet]. (acesso 18 maio 2013). Disponível: http://www.medicinabiomolecular.com.br/biblioteca/pdfs/Doencas/do0175.pdf

35. Kübler-Ross E. Sobre a morte e o morrer: o que os doentes terminais têm para ensinar a médicos, enfermeiras, religiosos e aos seus próprios parentes. $7^{\text {a }}$ ed. São Paulo: Martins Fontes; 1996.

\section{Participação dos autores}

Daniel Abreu Santos, Eduardo Robatto Plessim, Felipe Freire da Silva, Layo Henrique Carvalho e Leandro Anton de Azevêdo: interpretação dos dados, redação do artigo e versão a ser publicada. Nedy Maria Branco Cerqueira Neves: correção, análise crítica do artigo e versão a ser publicada.

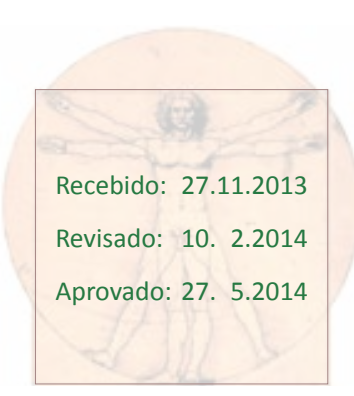

